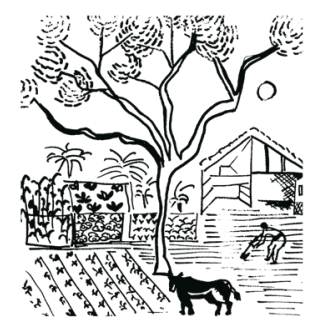

\title{
Redução do apoio público aos assentamentos: análise de uma resposta fundada em consumo solidário no assentamento Milton Santos
}

\author{
Samuel de Mello Pinto ${ }^{1}$ \\ Paulo Eduardo Moruzzi Marques ${ }^{2}$
}

\begin{abstract}
Resumo: Em razão do drástico desmantelamento dos programas de apoio público aos assentamentos de reforma agrária, emerge uma iniciativa de distribuição de cestas de alimentos orgânicos produzidos por famílias assentadas no projeto de desenvolvimento sustentável "Milton Santos", localizado em Americana/ SP e Cosmópolis/SP. Assim, desde o segundo semestre de 2017, foi formado no campus "Luiz de Queiroz" da Universidade de São Paulo em Piracicaba um coletivo solidário de compras destes produtos alimentares. Este artigo veicula uma análise desta experiência, mobilizando notadamente dados de uma enquete realizada junto a consumidores da cesta.
\end{abstract}

Palavras-chave: Alimentos orgânicos; Assentamento Rural; Circuitos curtos de comercialização; Economia local.

\section{REDUCTION OF PUBLIC SUPPORT FOR SETTLEMENTS: ANALYSIS OF A RESPONSE BASED ON SOLIDARY CON- SUMPTION IN THE MiLton SANTOS SETtLEMENT}

\begin{abstract}
Due to the drastic suppression of public policies to support rural settlements, an initiative of producer-consumer short circuit trade based on organic food baskets produced by families in the Sustainable Development Project "Milton Santos", located in Americana/SP and Cosmópolis/SP, was stablished. Thus, consumers related to the University of São Paulo's campus in Piracicaba/SP have organized a group to purchase these products, since the second semester 2017. This article presents an analysis of this experience, notably mobilizing data from a survey conducted with the consumers.
\end{abstract}

KEYWORDS: organic food, rural settlement, short food supply chains, local economy.

\footnotetext{
'Bolsista de iniciação científica do Programa Unificado de Bolsa (PUB/USP) 2017-2018. Graduando em Engenharia Florestal e Licenciatura em Ciências Agrárias, Escola Superior de Agricultura "Luiz de Queiroz" (ESALQ/USP), Piracicaba, SP. E-mail: samuel.mello@usp.br

${ }^{2}$ Professor Associado da Universidade de São Paulo, Escola Superior de Agricultura “Luiz de Queiroz”, ESALQ/USP e do Programa de Pós-Graduação em Ecologia Aplicada (CENA-ESALQ/USP). E-mail: pmarques@usp.br
} 


\section{INTRODUÇÃO}

Os profundos cortes nos investimentos públicos direcionados à reforma agrária nos últimos anos têm constituído um cenário de desestruturação de assentamentos em todo o Brasil. A extinção do Ministério de Desenvolvimento Agrário (MDA), em 2016, representou o desmonte da atuação pública na pauta agrária. De fato, este rearranjo institucional foi acompanhado de drásticas reduções orçamentárias do Instituto Nacional de Colonização e Reforma Agrária (INCRA), com repercussão em seus serviços de assistência técnica e extensão rural e em outros apoios aos assentamentos. Estes retrocessos da política agrária brasileira ameaçam a permanência das famílias assentadas no campo (LEITE; CASTRO; SAUER, 2018).

Inovações institucionais em termos do apoio à agricultura familiar, tal como o Programa de Aquisição de Alimentos (PAA), cuja concepção busca articular o desenvolvimento da produção familiar com o socorro alimentar a famílias em situação de vulnerabilidade social, são desmanteladas. De acordo com Vasconcelos et al (2019), de 2014 para 2018, houve uma redução de $67 \%$ do orçamento destinado ao programa, obstruindo importante canal de escoamento dos produtos das famílias assentadas. Efetivamente, a comercialização representa um dos principais gargalos para a agricultura familiar. Tais recuos do governo federal tornam muito maiores os desafios para o avanço da reforma agrária e para o fortalecimento da agricultura familiar.

Considerando a reforma agrária como um campo de intensa disputa política, Barone, Ferrante e Duval (2016) interpretam que um "grande ciclo" reformista teve início a partir dos anos 1980, associado ao processo de redemocratização do país. Conhecendo períodos de fluxos e refluxos, com maior ou menor apoio público, a questão agrária permaneceu na agenda política do país graças aos movimentos sociais do campo. Apesar dos seus evidentes limites em sua implantação, a reforma agrária desempenhou significativo papel associado à emergência de novos atores que se situavam a margem dos processos de desenvolvimento econômico, em especial nas periferias urbanas (BARONE; FERRANTE; DUVAL, 2016).

Desde o início dos anos 2000, a agenda da reforma agrária incorpora uma pauta ambiental consequente. O movimento social dos trabalhadores rurais sem terra passa a defender de forma cada vez mais incisiva uma orientação agroecológica para os assentamentos (BORSATTO \& CARMO, 2013). Por outro lado, no estado de São Paulo, a proposta do MST de Comunas da Terra e a implantação de assentamentos sob a modalidade de projeto de desenvolvimento sustentável (PDS) por parte do INCRA refletem esta inflexão. No primeiro caso, trata-se de assentar famílias nas proximidades de grandes centros urbanos, o que permitiria um melhor acesso a infraestruturas, serviços públicos e mercado consumidor. Com esta ótica, os projetos 
produtivos das Comunas da Terra devem se fundar na agroecologia, respondendo à demanda por alimentos orgânicos e agricultura limpa. Quanto ao PDS, sua concepção responde a uma perspectiva de conciliação da proteção ambiental com o desenvolvimento socioeconômico dos assentamentos. Formalizada graças à portaria no 477 do INCRA de 1999, esta modalidade atendia inicialmente reivindicações sociais da região amazônica. Em São Paulo, os assentamentos PDS apresentam diferentes desenhos de redistribuição de terras baseados na combinação de intenções de restauração ambiental e de adoção de modelos agrícolas menos impactantes (ALY Jr, 2011; BARONE; FERRANTE; DUVAL, 2016). Essa experiência também pode representar novos significados atribuídos à reforma agrária como resposta aos desafios ligados às mudanças climáticas (BARONE; FERRANTE; DUVAL, 2016).

Estas perspectivas de reinvenção da reforma agrária constituem um terreno fértil para o germinar de experiências de sistemas agroalimentares alternativos. Neste quadro, o objetivo deste estudo consiste em analisar os efeitos, por um lado, da redução dos apoios públicos, sobretudo do Programa de Aquisição de Alimentação (PAA), ao assentamento Milton Santos (situado parte em Americana/SP e parte em Cosmópolis/SP) e, por outro lado, da constituição de grupos de consumo solidário enquanto meio de escoamento dos produtos alimentares das famílias assentadas. Trata-se de avaliar o papel desse tipo de comercialização em termos de organização coletiva, evolução dos sistemas produtivos e participação na renda familiar, além de examinar o perfil dos consumidores solidários, considerando a experiência realizada na ESALQ/USP.

\section{Do PAA Ao CONSUMO SOLIDÁRIO}

Para Belik (2016), o acesso ao mercado é considerado condição chave para erradicação da pobreza rural, o que ressalta o papel do Estado na implementação de políticas que efetivamente apoiem os agricultores familiares neste âmbito. No assentamento Milton Santos, a comercialização de produtos via Programa de Aquisição de Alimentos (PAA) foi essencial para a consolidação do assentamento na medida em que efetivamente estimulou as atividades produtivas (MORUZZI MARQUES et al., 2016).

Resultado das mobilizações de famílias ligadas ao Movimento dos Trabalhadores Sem-Terra (MST) e da intervenção do Instituto Nacional de Colonização e Reforma Agrária (INCRA), o assentamento Milton Santos abriga 68 famílias desde 2005 numa área de 103,45 hectares. Idealizado como "Comuna da Terra", o assentamento se caracteriza, como mencionado anteriormente, por sua proximidade com grandes aglomerações urbanas, das quais muitos assentados são originários, e pela perspectiva de conciliação entre desenvolvimento produtivo e proteção ambiental, 
sob os pilares da agroecologia e da cooperação (MORUZZI MARQUES et al., 2016).

Como já considerado, as famílias assentadas puderam acessar o mercado institucional graças ao PAA, que estabelece uma ponte entre agricultores e pessoas em situação de vulnerabilidade social, via Companhia Nacional de Abastecimento (CONAB). Esta última estabelece um contrato com uma organização da agricultura familiar para fornecimento de alimentos em instituições de assistência social. O PAA representou um dispositivo chave para viabilizar o escoamento da produção do assentamento Milton Santos (MORUZZI MARQUES et al., 2016).

A propósito, Gaspari, Khatounian e Moruzzi Marques (2018) indicam que 51\% das famílias do assentamento tinham, em 2012, como principal fonte de renda a produção agrícola. Constituído predominantemente de hortaliças de ciclo curto, os alimentos produzidos eram comercializados via PAA em sua modalidade de Compra Direta da Agricultura Familiar com Doação Simultânea, o que oferecia segurança para comercialização e estímulo para produção.

Em razão dos cortes orçamentários do programa em questão, ocorreu grande desestímulo para a manutenção das áreas cultivadas. Neste quadro desolador, um grupo de agricultoras organizadas em torno de uma OCS (Organização de Controle Social) desenvolvem diferentes respostas visando revigorar os esforços em torno da atividade agrícola no assentamento. Convém aqui explicar que OCS é um dispositivo no âmbito do Ministério da Agricultura, Pecuária e Abastecimento de reconhecimento de qualidade orgânica para os casos em que o agricultor vende diretamente ao consumidor seus produtos ou os destina a mercados institucionais (neste caso, é possível obter uma majoração de 30\% no preço dos produtos fornecidos em relação àqueles convencionais) ${ }^{3}$. No assentamento Milton Santos, a primeira OCS foi formalizada com quatro famílias em 2015, contando com o apoio do Núcleo de Agroecologia da ESALQ/USP (MORUZZI MARQUES; GASPARI; ALMEIDA, 2017).

O relativo êxito desta primeira experiência estimulou a implantação de outros dois coletivos desta natureza: Horta Coletiva Produtos Orgânicos, com 11 famílias, e Terra Viva, contando com 8 famílias. Todas estes assentados estão inscritos no Cadastro Nacional de Produtores Orgânicos. Efetivamente, o processo de constituição da OCS reforça dinâmicas coletivas em grupos menores, permitindo a construção de diversas iniciativas conjuntas.

Desta forma, no seio da OCS Terra Viva, ocorre a criação de uma cooperativa em 2015, a COOPERFLORA (Cooperativa da Agricultura Familiar de Americana,

\footnotetext{
${ }^{3}$ Ver: http://www.agricultura.gov.br/acesso-a-informacao/acoes-e-programas/cartas-de-servico/desenvolvimentoagropecuario-cooperativismo-e-associativismo-rural/producao-organica
} 
Cosmópolis, Limeira e Piracicaba). Com efeito, tal cooperativa constitui a base de uma experiência das mais pertinentes no quadro atual para a comercialização dos alimentos das famílias assentadas. Trata-se da constituição de grupos de consumo solidário visando contribuir com o escoamento da produção, oferecendo ao mesmo tempo alimentos orgânicos a preços acessíveis graças a um circuito curto de comercialização. Nos últimos anos, muitas experiências desta natureza foram implantadas visando notadamente fortalecer a economia local, reduzir desperdícios, diminuir o deslocamento de alimentos em longas distâncias e promover a aproximação entre agricultor e consumidor.

Em princípio, o consumo solidário pressupõe uma aproximação entre consumidor e produtor, tornando mais transparente o processo de produção e de distribuição dos resultados, que se espera mais equitativa. Com um consumo fundado na solidariedade, espera-se também a promoção de outros valores de justiça e de qualidade da produção (SANTOS, 2012). Relações de consumo desta natureza são fundadas nos circuitos curtos de comercialização, cuja revalorização recente se associa a intenção de redefinir as relações entre produtor e consumidor, permitindo criar referências de qualidade vinculadas à origem e identidade cultural dos alimentos, bem como na capacidade de "ressocializar e reespacilizar a comida" (GOODMAN, 2009). Neste âmbito, dois tipos de comercialização podem ser identificados: 1. A venda direta permitindo uma interação intensa entre os atores, seja no próprio estabelecimento produtivo, mas também em feiras, lojas de associações de produtores e na forma de distribuição de cestas de alimentos em domicílio; 2. Venda indireta via um único intermediário, através de cooperativas, lojas especializadas ou mercados institucionais (DAROLT et al., 2016).

Dessa forma, os grupos de consumo solidário se inserem na primeira categoria, constituindo uma parceira mais ou menos formalizada entre produtores e consumidores graças à organização destes últimos. Na França onde ocorre grande desenvolvimento de experiências deste gênero, é ilustrativo o caso da AMAP (Associação para Manutenção da Agricultura Camponesa), a partir dos anos 2000, com grande engajamento dos consumidores em favor de agricultores com preocupações socioambientais (DAROLT et al, 2016). No Brasil, apesar de incipiente, observa-se o crescimento da comercialização através de cestas de produtos diversificados distribuídos para grupos de consumo solidário ou responsável (GONÇALVES; MASCARENHAS, 2017).

Nesse contexto, as famílias envolvidas na cooperativa fornecem cestas de alimentos semanais, majoritariamente orgânicos, para os membros dos grupos de consumo solidário na região (MENDONÇA; MORUZZI MARQUES, 2018). 
Atualmente, seis grupos desta natureza, localizados nos municípios de Americana, Campinas, Paulínia e Piracicaba, participam da rede de colaboração forjada pela cooperativa. Em Piracicaba, o grupo de consumo foi estabelecido no segundo semestre de 2017, no campus de Piracicaba da Universidade de São Paulo por iniciativa do Núcleo Nheengatu de Agroecologia da ESALQ/USP. De fato, equipes desta escola realizam atividades de apoio ao assentamento desde 2008, inicialmente com o grupo de extensão Territorialidades Rurais e Reforma Agrária (TERRA) e, a partir de 2012, também com o grupo Comercialização Justa e Cultura Alimentar (CAJAN), ambos pertencentes ao Núcleo de Agroecologia Nheengatu.

Este último nasceu em 2010 como forma de agregar e articular as iniciativas no âmbito da agroecologia e ampliar sua visibilidade na comunidade universitária. Nessa época, o Núcleo Nheengatu foi formado com quatro grupos de extensão, notadamente o TERRA, com grande atuação no assentamento Milton Santos. Atualmente, o Núcleo de Agroecologia conta com sete grupos de extensão e apoia o grupo de consumo solidário criado em Piracicaba, que é mantido e animado por CAJAN e TERRA. Os demais grupos também integram a iniciativa, com atuações voltadas a formações educativas e suporte pontual nas atividades, sobretudo no espaço de entrega das cestas.

É, efetivamente, graças aos grupos CAJAN e TERRA que a iniciativa foi concebida em 2017, com o objetivo de estabelecer um canal de comercialização da COOPERFLORA no campus da ESALQ/USP, inspirado no primeiro grupo de consumo criado pela própria cooperativa em Americana/SP no ano anterior. Além de fomentar um meio de escoamento dos produtos do assentamento, a criação do grupo de consumo em Piracicaba/SP foi considerada com uma oportunidade para dialogar com a comunidade universitária sobre a importância da agricultura de base ecológica, os benefícios dos circuitos curtos e o papel do Núcleo de Agroecologia.

\section{Metodologia}

Para a análise da ação da COOPERFLORA junto aos grupos de consumo solidário foram realizadas, ao longo do projeto, visitas mensais ao assentamento Milton Santos. A pesquisa focalizou os/as agricultores/as que integram a cooperativa, enfatizando a comercialização de sua produção. Dessa forma, foram realizadas observações participativas durante as vivências promovidas no âmbito das atividades dos grupos de extensão CAJAN e TERRA, como a oficina de planejamento produtivo realizada em 2018. Ademais, foram realizadas entrevistas semiestruturadas junto a lideranças da cooperativa. A análise dos dados procurou identificar mudanças e continuidades a partir da constituição dos grupos de consumo 
solidário sob três perspectivas: a organização coletiva, a evolução dos sistemas produtivos e a contribuição da comercialização solidária na renda familiar.

Por outro lado, a avaliação da experiência do grupo de consumo solidário da ESALQ/USP teve como base: 1. A realização de duas enquetes com os consumidores das cestas, a primeira no final de junho de 2018 e a segunda em dezembro de 2018, visando identificar suas motivações e suas preferências quanto à qualidade e quantidade dos alimentos; 2. A quantificação do número de pedidos de cestas durante o ano de 2018; 3 . A análise da gestão do referido grupo de consumo durante o desenvolvimento da iniciativa ${ }^{4}$.

\section{A ANÁlise da EXPERIÊnCIA DE IMPLANTAÇÃo de GRUPOS DE CONSUMO SOLIDÁRIO}

Convém inicialmente detalhar um pouco mais o processo de constituição da COOPERFLORA. De fato, sua criação contou igualmente com o impulso decisivo de atividades desenvolvidas no assentamento em 2015 em torno de uma pedagogia crítica no âmbito do projeto local de Educação de Jovens e Adultos (EJA) junto a agricultores que desejavam se alfabetizar ${ }^{5}$. Com efeito, discussões sobre ações coletivas e sobre alternativas de produção e comercialização com vistas a melhorar a qualidade de vida dos assentados levaram à proposta de constituição da cooperativa:

...com a sala do EJA nós ficávamos discutindo o que poderia ser feito para melhorar a vida das pessoas aqui dentro e para organizar um pouco melhor nós enquanto comunidade. Aí com a sala do EJA a gente foi debatendo, debatendo junto com os alunos e decidimos montar uma cooperativa (entrevistado da COOPERFLORA, 2018).

Desde sua criação, são vinte seis famílias que compõem a organização, das quais somente doze efetivamente produzem e comercializam via cooperativa. Trata-se de um número reduzido em relação ao total de famílias assentadas (68), refletindo uma dificuldade de organização coletiva. Efetivamente, o assentamento contou com uma organização (ACOTERRA, Associação Comuna da Terra local) que englobava todas as famílias assentadas, cumprindo sobretudo o objetivo de intermediar sua participação no PAA. Com a redução progressiva do apoio deste programa ao assentamento, a associação em questão se desestruturou, deixando lugar para estruturas mais diminutas, em particular as OCS. A cooperativa, com um formato mais enxuto, promove com efeito uma maior interação entre os agricultores,

\footnotetext{
${ }^{4}$ Este trabalho foi concebido antes de tudo como um meio de aperfeiçoar a iniciativa, com a produção de conhecimentos consistentes para o diálogo entre os membros dos grupos de extensão e os assentados.

${ }^{5}$ Tratou-se de uma parceria envolvendo notadamente o Movimento de Educação de Base (MEB) e o MST (Silva, 2015).
} 
sobretudo entre aqueles que já colaboravam entre si.

As famílias ativas na cooperativa, produzindo alimentos para as cestas fornecidas aos grupos de consumo solidário, buscam se organizar de forma que haja uma produção diversificada, com divisão de cultivos entre os agricultores. Assim, almeja-se que todos tenham as mesmas chances de comercializar, em quantidades similares, os alimentos distribuídos. Na ponta do consumo, a intenção é que se ofereça importante diversidade de alimentos nas cestas.

Para tal objetivo, às sextas-feiras, este coletivo se reúne para contabilizar os pedidos de cestas, considerando todos os grupos de consumo. Estes últimos possuem dinâmicas específicas que não serão tratadas neste artigo. Com efeito, nosso foco aqui se dirige ao grupo de consumo do campus da ESALQ/USP, o que será abordado no item seguinte. Brevemente, cada grupo de consumo informa a cooperativa o número de pedidos de cestas, conforme sua frequência de funcionamento, para que na reunião semanal referida acima os produtores possam se organizar para atendê-los.

Portanto, nesta ocasião, há a divisão do que cada agricultor fornecerá. Caso, por exemplo, um produtor não possa assegurar a entrega de determinado alimento, outro agricultor é convidado a contribuir. De fato, o planejamento da produção apresenta uma série de fragilidades ${ }^{6}$.

Com efeito, os agricultores em geral têm dúvidas sobre as culturas que devem plantar em determinada época, sobre a quantidade de mudas ou sementes que devem empregar e sobre práticas de manejo. A propósito, considerando que o planejamento produtivo constitui uma peça chave para a organização dos cooperados e que sua prática é incipiente entre os agricultores, oficinas sobre a questão foram realizadas pelos grupos de extensão TERRA e CAJAN, em particular com o objetivo de orientar sobre as formas de diversificar os cultivos, sobre seus ciclos produtivos e épocas de plantio, utilizando-se de recursos didáticos como uma roda de sazonalidade e calendários de plantio (Figura 1).

Por outro lado, vale a pena mencionar que, apesar do PAA ter representado um canal muito favorável à comercialização dos produtos das famílias assentadas, havia pouca atenção em relação à qualidade dos produtos. Segundo nossos interlocutores, o interesse era, antes de tudo, fornecer a quantidade em quilos dos alimentos previstos nos projetos financiados pela CONAB. Esta comercialização junto ao PAA englobava essencialmente hortaliças de ciclo curto e poucas frutas existentes nos lotes.

${ }^{6}$ Outra dificuldade se refere ao fato que grande parte deste grupo é constituída por mulheres entre 50 e 70 anos, com núcleo familiar reduzido (algumas vivendo só). Essa limitada força de trabalho dificulta o desenvolvimento de uma produção agroecológica. 
Figura 1- Oficina de planejamento produtivo realizada com os cooperados.

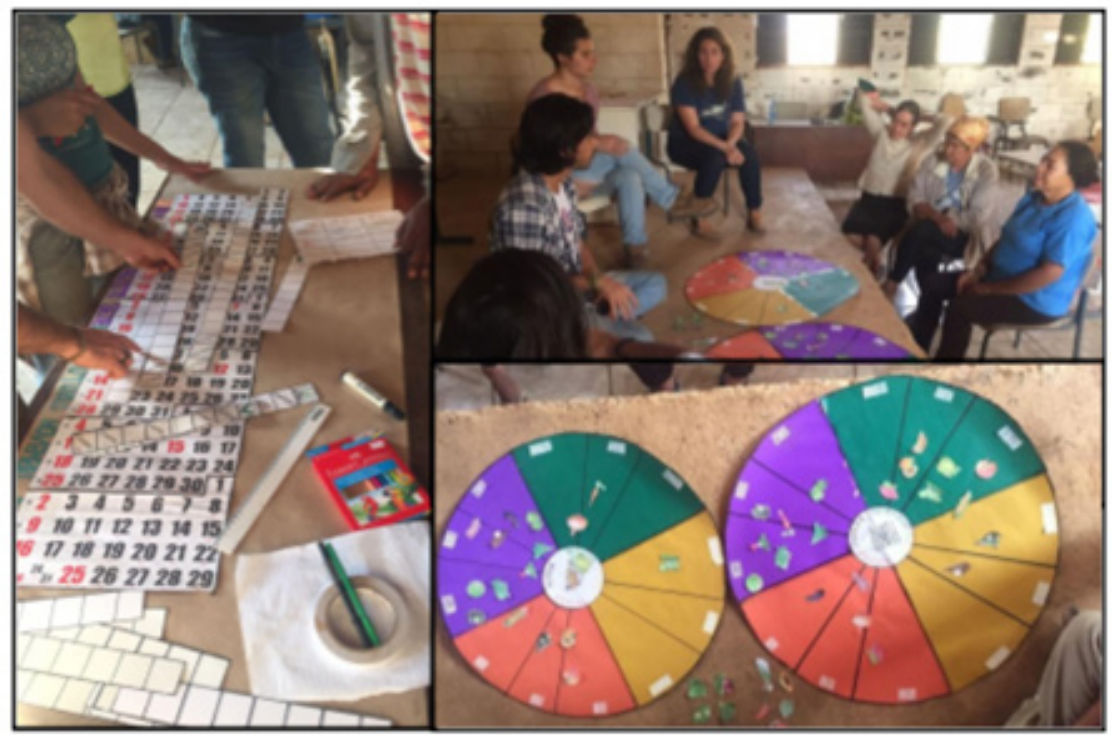

Fonte: Acervo do grupo CAJAN.

Com a comercialização via cooperativa para os grupos de consumo solidário, nossos entrevistados mencionam que precisaram "ter muito mais cuidado com o alimento". Em primeiro lugar, a OCS permite assegurar que se trata de produto orgânico, o que não era o caso do fornecimento para o PAA. Além do cuidado com o manuseio e da qualidade orgânica, atenção é igualmente dirigida para a diversidade. As cestas de alimentos contam assim entre 5 a 6 produtos diferentes, como folhosas, legumes, frutas, além de pelo menos um produto processado ${ }^{7}$. Assim, o desafio consiste em adaptar os sistemas produtivos a essa nova demanda de diversidade de produção.

Quanto à renda familiar, grande parte dos cooperados tem como principal fonte de renda a aposentadoria. Os recursos obtidos com a comercialização via cooperativa são assim um complemento. De toda maneira, os dados obtidos em nossas pesquisas de campo revelam que nossos interlocutores preferem entregar seus produtos à cooperativa em comparação a comercializar seus alimentos via PAA. As desvantagens deste último se referiam notadamente ao longo prazo para receber o pagamento pelos alimentos fornecidos, podendo chegar a três meses de espera.

Além do atraso no pagamento, o PAA previa remuneração de acordo com o peso dos produtos, com uma cota estabelecida para cada agricultor. No caso da

${ }^{7}$ Outra característica interessante permitida pelos grupos de consumo se refere à maior liberdade para ofertar produtos pouco conhecidos, como é o caso das plantas alimentares não convencionais (PANCs). 
cooperativa, a remuneração por unidade de produto é considerada como melhor, o preço sendo fixado não pelo peso, mas pelo tipo e quantidade.

Em contraposição, as vendas via cooperativa apresentam maior oscilação em termos de número de cestas entregues, dependendo do período do ano. Ou seja, a variação pode ser de 20 a 100 cestas no período de poucas semanas, revelando grande instabilidade, o que não ocorria com a mesma proporção no PAA no momento de seu auge.

\section{A EXPERIÊNCIA DO GRUPO DE CONSUMO SOLIDÁRIO NA ESALQ/USP}

Em relação à sua dinâmica, os procedimentos de comercialização das cestas do grupo de consumo da ESALQ/USP têm início com a abertura de pedidos via internet, em uma plataforma chamada "typeform", na qual são solicitadas as informações "nome", "contato" e "número de cestas desejadas". Esse formulário é então encaminhado através do e-mail institucional da USP de forma que todos os estudantes, professores e funcionários do campus sejam informados da abertura da plataforma para recebimento de pedidos. Desde agosto de 2019, a divulgação não ocorre mais pelo canal institucional, mas por diferentes meios mais informais, como as mídias sociais do grupo de extensão CAJAN e do Núcleo Nheengatu de Agroecologia. Uma vez encerrado o período de solicitações de cestas pelo formulário, contabiliza-se o número total de pedidos, o que será informado aos membros da COOPERFLORA que por sua vez se organizam para entregar o rol de alimentos solicitados.

Como já mencionado, as cestas são compostas por seis alimentos, majoritariamente orgânicos, apresentando uma diversidade de folhosas, legumes, frutas e produtos processados. No segundo semestre de 2019, seu valor alcança R\$ 20,00, ao qual é acrescido o custo do transporte para Piracicaba. Assim, a cesta é comercializada a R \$25,00 junto ao consumidor da ESALQ/USP. Por questão logística e organizacional do grupo gestor do projeto, as cestas são comercializadas quinzenalmente.

Em 2018, a média dos pedidos foi de 30 cestas por entrega (o menor número foi de 14 unidades, no dia 16 de outubro, e o maior número de 51, no dia 21 agosto, tal como apresentado na Figura 2). Observa-se, portanto, uma oscilação considerável quanto ao número de pedidos, o que pode estar relacionado a múltiplos fatores como a) o alcance da divulgação do projeto na semana anterior as entregas; b) o calendário da universidade; c) o fechamento do restaurante universitário durante três meses em 2018, o que pode ter influenciado no alto número de pedidos entre os meses de agosto e setembro e; d) o grau de satisfação com as cestas da semana, 
o que motiva realizar um novo pedido. Como o projeto em 2018 completou apenas um ano, ou seja, 13 entregas, tratou-se de uma fase de consolidação. Portanto, estas interpretações são preliminares.

Figura 2 - Número de cestas entregues na ESALQ/USP em 2018.

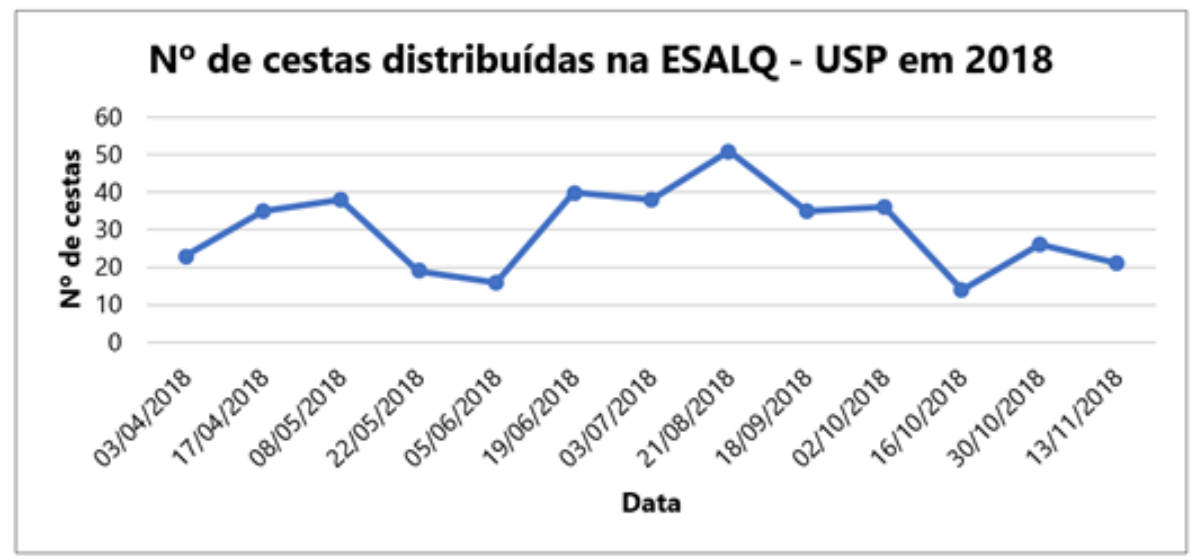

Fonte: Elaborado pelos autores.

Quanto ao perfil dos consumidores, foram enviados por e-mail, para todos que já haviam realizado pedidos, dois questionários, um em junho/2018 e outro em dezembro/2018 para obter seus pontos de vista sobre as cestas. Dos 159 consumidores contatados ao total, $23,27 \%$ responderam ao questionário. Deste universo, a maioria é composta por funcionários públicos e estudantes, como mostra a Figura 3, e conheceram o projeto pelo e-mail institucional da ESALQ/USP.

O consumo de produtos orgânicos representa o fator que gera mais motivação para participar deste projeto de distribuição de cestas de alimento, com 16 respondentes apontando essa razão. Porém, são 27 aquelas respostas que se associam a uma "solidariedade alimentar", com as seguintes perspectivas, incentivar o pequeno produtor, a agricultura familiar, a agroecológica ou o grupo em razão de seu viés social. Ainda nesta perspectiva, três interlocutores mencionam o apoio ao consumo responsável e à reforma agrária (Figura 4).

A frequência dos pedidos revela que não se constituiu claramente uma fidelização ao projeto, sendo que apenas $19 \%$ dos consumidores manifestam compromisso de compra frequente junto ao projeto (Figura 5). As sugestões para sua melhora permitem considerar os pontos que poderiam ser aperfeiçoados para que haja, portanto, maior comprometimento dos consumidores com vistas à consolidação da iniciativa (Quadro 1). Em ambas as enquetes, destacaram-se as seguintes sugestões: 
oferta das cestas em tamanhos diferentes, com menor quantidade de produtos se comparada à configuração atual; divulgação prévia dos produtos no momento da solicitação da cesta e; maior diversidade de produtos na cesta.

Figura 3 - Principal atividade atual dos consumidores respondentes

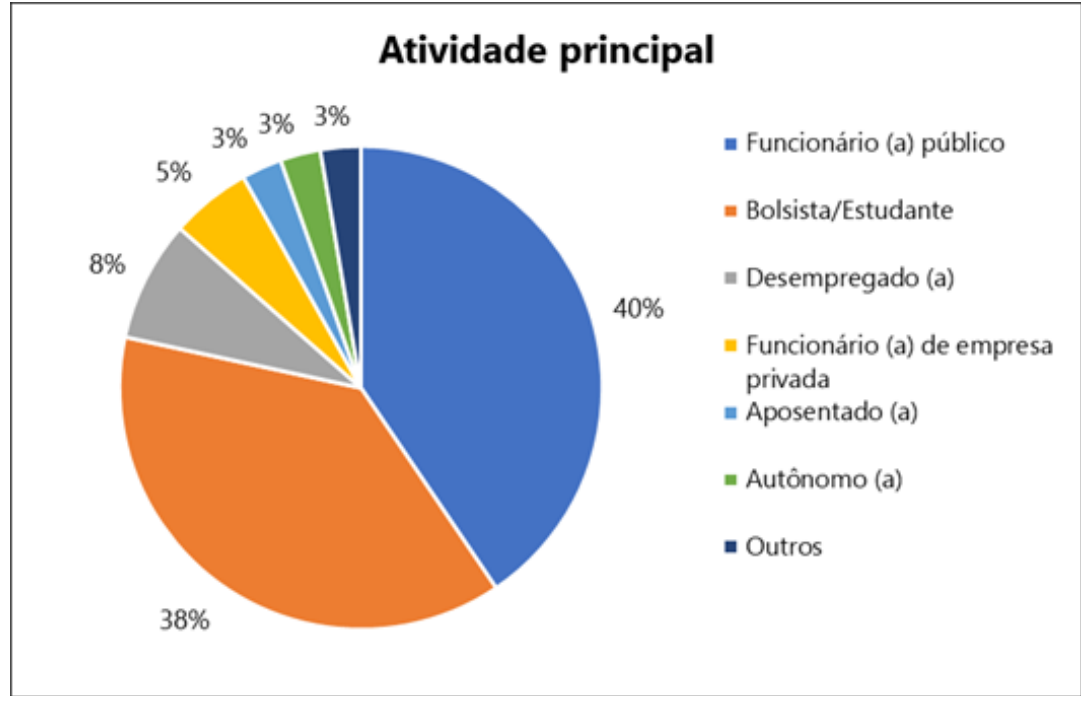

Fonte: Elaborado pelos autores.

Figura 4 - Motivação dos consumidores.

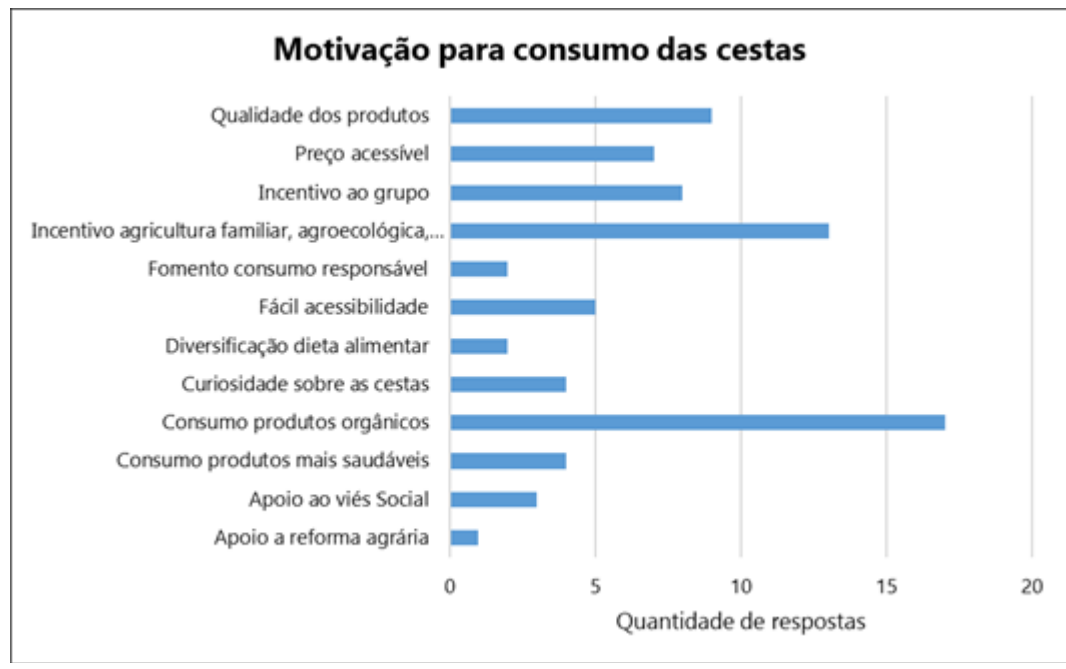

Fonte: Elaborado pelos autores.

Figura 5 - Frequência de encomenda das cestas no ano de 2018, correspondente 
a 13 eventos de entrega.

\section{Frequência de encomenda}

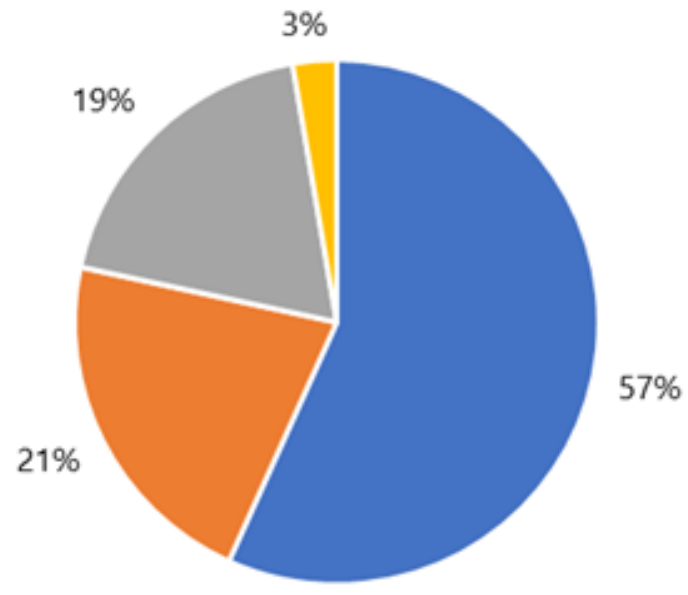

- Apenas 1 ou 2 vezes

= Ocasionalmente

= Sempre

- Uma vez ao mês

Fonte: Elaborado pelos autores.

Quadro 1- Sugestões dos consumidores a equipe gestora do grupo de consumo e aos produtores.

\section{Sugestōes propostas pelos consumidores}

\begin{tabular}{l}
\hline A) melhorar a variedade dos produtos entregues \\
\hline B) divulgar melhor os itens avulsos previamente \\
\hline c) usar menos sacos plásticos \\
\hline d) divulgar o projeto para além da universidade \\
\hline e) possibilitar a troca de produtos que não irá consumir \\
\hline f) prévia dos possíveis produtos \\
\hline g) diminuição do tamanho das cestas \\
\hline h) apresentar receitas com os produtos \\
\hline i) oferecer semanalmente \\
\hline j) fornecer mais PANC e sugestర̋es de uso \\
\hline k) realizar encontros com os assentados na universidade para dar mais visibilidade à venda e desmistificar paradigmas \\
\hline l) fornecer mais opçøees na hora de pegar as cestas
\end{tabular}

Fonte: Elaborado pelos autores. 
O desengajamento do governo brasileiro com a política de reforma agrária acentua as grandes dificuldades das famílias assentadas, em particular no que se refere à comercialização de seus produtos. $\mathrm{O}$ desmonte do Programa de Aquisição de Alimentos constitui um exemplo dos mais eloquentes deste abandono da ação pública em favor dos agricultores familiares, especialmente os assentados.

Neste quadro, os grupos de consumo solidário passaram a representar a principal via de comercialização no assentamento Milton Santos, especialmente via COOPERFLORA. Muitos são os desafios para tornar este canal mais consistente, sobretudo no que se refere à organização e planejamento da produção e a uma maior diversidade dos produtos ofertados.

Por outro lado, a análise das respostas dos consumidores solidários interrogados da ESALQ/USP permite constatar que o projeto não permitiu a constituição de um compromisso mais efetivo de solidariedade com as famílias agricultoras do assentamento Milton Santos. Ajustes em termos de ampliar horários de distribuição das cestas, com mais quantidade de produtos, além de um trabalho comunicativo de sensibilização ao projeto, são propostas apresentadas que podem indicar formas para obter mais engajamento dos consumidores no projeto.

Seja como for, o número importante de respostas em nossas enquetes que apresentam uma perspectiva de "solidariedade alimentar" indicam a compreensão da essência deste projeto de distribuição de cestas alimentares. A continuidade das análises sobre sua evolução é bastante pertinente para estimular a reflexão e o debate sobre os valores difundidos em torno da iniciativa e sobre o grau de engajamento dos consumidores solidários.

\section{REFERÊNCIAS}

ALY JUNIOR, O. Projetos de Desenvolvimento Sustentável (PDS) e os desafios na construção de novas políticas de assentamento. Retratos de Assentamentos, [S.1.], v. 14, no 2, p. 283-304, 2011.

BARONE, L.A.; FERRANTE, V.L.S.B.; DUVAL, H.C. A reforma agrária que temos: revisitando uma polêmica acesa. Política \& Trabalho, nº 45, p. 25-45, 2016.

BELIK, W. Circuitos de agricultura familiar no Brasil: notas para discussão. In: DELGADO, G.C.; BERGAMASCO, S.M.P., orgs. Agricultura Familiar Brasileira: Desafios e Perspectivas de futuro. Brasília: Ministério do Desenvolvimento Agrário, p. 223-244, 2017. 
DAROLT, M.R.; LAMINE, C.; BRANDENBURG, A.; ALENCAR, M.C.F.; ABREU, L.C. Alternative Food Networks and New Producer-Consumer Relations in France and in Brazil. Ambiente \& Sociedade. São Paulo, v. 19, n 2, p. 1-22, 2016.

GASPARI, L. C.; KHATOUNIAN, C. A.; MORUZZI MARQUES, P. E. . O papel da agricultura entre as famílias pluriativas assentadas em região metropolitana: o caso do assentamento Milton Santos em Americana e Cosmópolis/SP. NERA (UNESP), v. 21, p. 85-101, 2018.

GOODMAN, D. Place and space in alternative food networks: Connecting production and consumption. Department of Geography. King's College London. 36p. 2009.

GONÇALVES, J; MASCARENHAS, T. As várias faces do sistema alimentar e a experiência da Rede Brasileira de Grupos de Consumo Responsável. In: Consumo Responsável em Ação: Tecendo relações solidárias entre o campo e a cidade. São Paulo: Instituto Kairós, 2017. p. 71-87.

LEITE, A. Z.; CASTRO, L. F. P.; SAUER, S. A questão agrária no momento político brasileiro: liberalização e mercantilização da terra no estado mínimo de Temer. OKARA: Geografia em debate, João Pessoa, v. 12, nº 2, p. 247-274, 2018.

MENDONÇA, G. M.; MORUZZI MARQUES, P. E. Protagonismo feminino na agricultura agroecológica: estudo de uma organização de controle social no assentamento Milton Santos. Retratos de Assentamentos, v. 21, n 2, p. 47-67, 2018.

MORUZZI MARQUES, P. E.; KHATOUNIAN, C. A.; GASPARI, L. C.; RETIERE, M. Justificações em torno de assentamento periurbano da modalidade projetos de desenvolvimento sustentável (PDS) no estado de São Paulo: uma justiça ecológica em questão. Retratos de Assentamentos, v. 19, nº 1, p. 21-40, 2016.

MORUZZI MARQUES, P. E.; GASPARI, L. C.; ALMEIDA, B. Organização de Controle Social (OCS) e engajamento agroecológico das famílias do assentamento Milton Santos no estado de São Paulo. Estudos Sociedade e Agricultura, v. 25, $n^{\circ}$ 3, Rio de Janeiro: CPDA/UFRRJ, p. 545-560, 2017. 
SANTOS, L. L. A educação para o consumo no espaço da escola: criando as bases para o consumo crítico e solidário. Reflexão e práticas em Educação Ambiental: discutindo o consumo e a geração de resíduos. São Paulo: Oficina de Textos, p. 69-89, 2012.

SILVA, R. A. Jovens do assentamento Milton Santos: sentidos do trabalho e da educação. Dissertação de Mestrado do PPG em Educação. Sorocaba: UFSCar, 2015.

VASCONCELOS, F.A.G.; MACHADO, M.L.; MEDEIROS, M.AT.; NEVES, J.A.; RECINE, E.; PASQUIM, E.M. Public policies of food and nutrition in Brazil: From Lula to Temer. Revista de Nutrição. v. 32, p. 1-13, 2019. 